\title{
Introduction
}

\section{Global Perspectives on Educational Improvement in Post-COVID-19}

\author{
Melody VICZKO \\ Associate Professor of Critical Policy Studies, Equity and Leadership Studies, \\ Faculty of Education, Western University, London, Canada \\ mviczko@uwo.ca \\ Jun LI \\ Professor of Critical Policy Studies, Equity and Leadership Studies, Faculty of \\ Education, Western University, London, Canada \\ jun.li@uwo.ca
}

The global pandemic of CoviD-19 has spurred urgent demands for and radical responses from educational institutions, bringing about increasing concerns for both the short-term and long-term effects of improvement on education. Educational improvement "is often defined as a process as well as an approach of advancement in education at individual, institutional, systematic, national and/or global levels" (Li, 2021), and educational improvement studies (EIS) as a field has drawn increasing global attention in recent years, with critiques of the narrowed outcomes of intended reform in an intensified era of innovation (Bryk et al., 2015; Lewis, 2015). The critiques to the global mobility of improvement agendas already exist for the failure of initiatives to address local concerns of social justice in education and for the damaging effects of standardization and rankings, including PISA, TIMMS, TALIS, ICCS, etc. Additionally, emerging approaches to research have aimed at understanding the influences of "big data" driven reforms within improvement initiatives on educational organizations, practices and professionals. Given these concerns, the unprecedented 
shifts in institutional responses to COVID-19 require approaches aimed at ensuring equity, quality and diversity of education.

The crisis of the pandemic intersected with many injustices on a global scale: the Black Lives Matter Movement and the Movement against Anti-Asian, Asian-American and Pacific Islander (AAPI) Racism in the US that called attention (again) to the extent of systemic anti-Black and Anti-Asian in institutions in Canada; the recent revelation of more than 1,00o Indigenous children's bodies in unmarked graves in the grounds of a former residential school; the inequities of global cooperation made visible through efforts to mobilize vaccines across national borders; school closures and their impact on learning as the shift to online teaching had devastating effects on access to education for many children where remote learning options were non-existent or challenging. Given the intersections of the pandemic with existing global crises, the call for papers in this special issue asked scholars and researchers to consider how we might think of what it means to leverage policies and practices aimed at school/higher education improvement in the era of a post-CoviD-19 period. Furthermore, the needs emerging from pandemic are truly complex, given the dispersed implications across economy, society and institutions (Shultz \& Viczko, 2021) and the ability to address the implications on education is perhaps best characterized as a wicked policy problem (Rittel \& Webber, 1973). Nonetheless, the articles featured in this issue hold a common theme - that efforts aimed at improvement cannot be successful without consideration that, perhaps more than ever, education is never just about developing skills or academic achievements. Rather, education at all levels is ultimately humanity work which always serves as the foundation and vision desirable for any improvements in the sector and beyond.

The articles bring together considerations for improving education across three national contexts: Canada, Poland and the US. The studies featured in the issue bring eclectic perspectives of education, from emergency education programming with newcomer youth to rapid shifts to online teaching and pedagogies with university students to leadership education programs aimed at social justice values and principles in school systems. This breadth of topics helps to illuminate that the pandemic has left no education context untouched. What is left to consider is how to make our way to a more just education as we face recovery in and new normality after the pandemic. The articles offer hope for moving forward, and their messages of hope point to policy and practice directions that deserve our attention.

Thashika Pillay, Setarah Ghahari, Merin Shobhana Xavier, Halima Wali, Suchetan James, Muhammad H. Sani and Liby Alexander bring a community-based approach to research to understanding the impacts of the pandemic on newcomer youth in a city in Canada. This article is novel in how 
the authors highlight the strength of the diversity of the research team consisting of a local immigrant-serving agency, local school board and educators, and a group of interdisciplinary university researchers. The article reports on a qualitative study using interviews with high-school aged youth and parents of elementary school students to illuminate newcomer youth's experiences of shifting to online forms of learning. The authors argue that the pandemic exacerbated the inequities embedded in the structural problems of the educational system, showing the challenges that students encountered in the rapid shift to online learning, including breakdowns in communication, lack of connections with parents, stressful conditions of online learning, and gaps in coordination between the school systems and community-based supports. The authors discuss that school-community-family partnerships are crucial in a post-pandemic era, as is the community-based approach to understanding the educational needs of students and their families. Furthermore, funding models must prioritize an acknowledgement of newcomer youth as knowledge partners rather than objects of intervention in order to ensure their voices are instrumental in re-shaping education practices.

Ana Godonoga and Danuta Gruszka share a view into the impacts of the COVID-19 pandemic on Polish universities, from the perspective of university students. Drawing on strategic crisis management theory, the article points to the way in which the globalized shift towards New Public Management has become a key policy agenda in contemporary higher education systems in Poland, leading to rapid expansion, discourses of fiscal restraint that require "doing more with less" and decentralized systems. However, as the authors point out, the COVID-19 pandemic has led to circumstances where the efforts at control embedded within strategic management in the university system come head-to-head with the uncertain terrain of crisis, requiring more robust and responsive measures to act quickly, with little opportunity for long-term thinking. Seeking to understand how students experienced the shift to online learning during this rapid period of crisis and change, the authors discuss the findings from a survey of students in Polish universities, indicating there were mixed views about teaching and learning in the move to online learning. The findings from the study provide important insight to initial understanding of students' perceptions of this radical shift as Polish universities acted decisively before receiving policy directives from the national government. Of note is that first-year students expressed the most concern about needing support systems. The study offers important considerations for leaders in higher education institutions to reflect on their role in ensuring access for students, relationships between policies in $\mathrm{HE}$ and the students who experience them as policy subjects. 
Shibao Guo and Yan Guo's article sheds light on the deep roots of anti-Asian racism in Canada, as rendered glaringly visible during the COVID-19 pandemic. Guo and Guo's contribution provides an impressive historical review of anti-Chinese, and anti-Asian racism more generally, in the Canadian landscape, as well as a deep interrogation of the literature in these areas. Drawing on critical race theory, Guo and Guo offer a pointed critical analysis of current incidents that were reported in popular press during the pandemic that brought public attention to deeply rooted racial discrimination and xenophobia emerging as a continual crisis in Canadian societies. Arguing for a framework of pandemic anti-racism education, the scholars indicate the political and social aspects of educational improvement both within classrooms but also into the public sphere, requiring that "educators acknowledge the existing inequities in educational structures and environments, understand their role in these structures and actively advocate for change. With this objective, the role of teachers and instructors extends from the sphere of the classroom into the community and requires engaging with social and political issues. Educators need to explicitly teach pandemic anti-racism and develop awareness of discursive racialization and xenophobic violence and discrimination in relation to CoviD-19 and discuss action plans to eliminate them" (this issue). Their work here, indeed, is a powerful model for moving forward.

Juan Manuel Niño considers how educational leadership practices were transformed for those in three southwest Texas school districts when teaching and learning modes switched to e-learning modes. Using interviews with graduate students enrolled in a program that focuses on social justice perspectives in educational leadership, Niño examined how educational leaders took up intersectional approaches to equity as they were embedded in course readings, discussions, and assignments as part of the program. Theoretically this program draws on Freire's (1974) critical consciousness centered on "finding yourself, knowing who you are, and understanding the world in a way that does not dehumanize people" (this issue). Freire's (1974) work is used as the foundation for the USLC pedagogy. In this article, Niño argues the findings position teachers' agency as a key aspect of providing learning opportunities to the predominantly Latino students. Educational leaders spoke about the urgency to ground learning in the real problems students faced in their lives related to the pandemic, and that the critical consciousness of care learned in the programming graduate education program guided their sense of agency. The findings from the study provide contemporary and up-to-date insights of how the covid19 pandemic is making an impact on practitioners' professional thinking and engagement with students. 
Charlais (Cee) Carter and Kimberley McIntee also focus on the American context in an examination of education change policies as they intersect with the crisis of the pandemic. Using a policy document analysis approach, the scholars draw on Leigh Patel's call for a methodological stance of "pausing", a compelling counterargument to the rush and speed by which responses in some education contexts were carried out. In this article, Carter and McIntee consider how and whether the U.S. federal government's plans for educational equity and accountability is answerable to Black, Indigenous, and students of color in the context of the global pandemic, the switch to remote learning, and global uprisings for Black lives. Their analysis is astute and troubles the extent to which educational responses for addressing the learning of Black, Indigenous and other racialized students has fallen from national attention during the pandemic. Like other articles in this special issue, they offer hope for positing alternative approaches, steeped in pedagogies and policies that can bring about justice in pandemic recoveries.

The five articles provide new insights on the ongoing discourse on educational improvement in post-Covid-19, and contribute to the emerging field of EIS in novel ways, which are not confined by the conventional, technocratic approach of school effectiveness. The implications the authors make are of great help for us to more critically reflect on what are largely missing or neglected in the global quest for educational improvement.

\section{References}

Bryk, A. S., Gomez, L. M., Grunow, A., \& LeMahiue, P. G. (2015). Learning to improve: How America's schools can get better at getting better. Harvard Education Press.

Freire, P. (1974). Pedagogy of the oppressed. Seabury Press.

Lewis, C. (2015). What is improvement science? Do we need it in education? Educational Researcher, 44(1), 54-61.

Li, J. (2021). Educational Improvement for World-Class Teachers? A Critical Analysis of Policy Implementation in China. In X. Zhu \& H. Song (eds.), Envisioning teaching and learning of teachers for excellence and equity in education. Springer. https://doi. org/10.1007/978-981-16-2802-3_5.

Rittel, H. W. J., \& Webber, M. M. (1973). Dilemmas in a general theory of planning. Policy Sciences, $4(2), 155^{-169}$.

Shultz, L, \& Viczko, M. (2021). What are we saving? Tracing governing knowledge and truth discourses in global COVID-19 policy responses. International Review of Education. doi: 10.1007/s11159-021-09893-y. 